\title{
Oligoaniline-containing electrochromic polymers with tunable properties
}

\author{
Y. $\mathrm{Li}^{1}$, X. Jia ${ }^{2}$, Y. Zhou ${ }^{1}$, D. Chao ${ }^{*}$ \\ ${ }^{1}$ Alan G. MacDiarmid Institute, College of Chemistry, Jilin University, 130012 Changchun, P.R. China \\ ${ }^{2}$ ARC Centre of Excellence for Nanoscale BioPhotonics (CNBP), Macquarie University, NSW 2109 North Ryde, Australia
}

Received 6 December 2017; accepted in revised form 24 February 2018

\begin{abstract}
Electrochromic polymers have attracted much attention due to their potential applications in displays, smart windows, intelligent mirrors, and wearable devices. Here, a novel polyamic acid containing aniline pentamer with improved electrochromic properties and new functionalities was synthesized via oxidative coupling polymerization, followed by postpolymerization of tetraaniline, polyhedral oligomeric silsesquioxane, and fluorene, respectively. With the introduction of tetraaniline pendants, the resultant polymer exhibits improved electrochromic performance with high optical contrast value and rapid switching rate, because of the high content of electrochromic units in the polymeric structure. The polyamic acid functionalized with polyhedral oligomeric silsesquioxane, demonstrates a great enhancement of switching rate in the electrochromism, due to the rapid electrolyte migration through polymer film under electrochemical potentials. In addition, a new electrofluorochromic feature is easily achieved through the introduction of fluorescent fluorene groups into the polymeric architecture.
\end{abstract}

Keywords: smart polymers, electrochromic, oligoaniline, electrofluorochromic, electroactive

\section{Introduction}

Conjugated polymers are promising electrochromic materials, due to their tunable properties through molecular design and synthesis [1-5]. The vast toolbox of organic chemistry enables facile chemical engineering of molecular structure to improve electrochromic performance. The intrinsic synthesis-structure-electrochromic performance relations have also been investigated and determined. Among various electrochromic polymers, polyaniline has received intensive interest because of its low redox potentials, high electroactivity, and multiple color switching characteristic [6-10]. Likewise, several synthetic tactics have been explored and employed to enhance the electrochromic properties of polyaniline-type polymers. For example, Pinit et al. [11] synthesized poly $(o$-toluidine) via electrochemical polymerization on a flexible indium tin oxide (ITO) sheet using two supporting electrolytes. The resultant poly(o-toluidine) displayed many distinct colors with short switching times: from colorless to yellow, to green, and finally to blue. 2,5-Dimethoxyaniline was also utilized to prepare electrochromic poly(2,5-dimethoxyaniline) using electrochemical polymerization. The polymer showed reversible color change from yellow to blue under the potential switching $[12,13]$. A novel conducting copolymer, poly(aniline- $\mathrm{co}-\mathrm{N}$-methylthionine), was synthesized in a mildly acidic aqueous solution using cyclic voltammetry [14]. An obvious black to transmissive electrochromic behavior was achieved under relatively low potentials. Chotsuwan et al. [15] synthesized a novel soluble polyanilinepolythiophene-polyaniline tri-block copolymer. The resultant film revealed an improvement of stability during the electrochromic process. Although the electrochromic properties of polyaniline-type polymers

$\overline{{ }^{*} \text { Corresponding author, e-mail: chaodanming@,jlu.edu.cn }}$

(C) BME-PT 
have been effectively enhanced by virtue of some exquisite synthetic strategies, there remains a need to synthesize more electrochromic polyaniline-type polymers with outstanding characteristics and new features.

As model compounds of polyaniline, oligoanilines possessed well-defined molecular structure, superior solubility, and tunability, while preserving polyaniline's functionalities. Therefore, oligoanilines have recently been used as an electroactive unit for the preparation of electrochromic polymers. So far, many oligoaniline-containing electrochromic polymers have been designed and synthesized [16-19] through two strategies: (1) direct polymerization of oligoanilinefunctionalized monomers, and (2) post-functionalization of existing polymers using oligoaniline groups. In our group, some additional functional groups, such as azobenzene, sulfoacid, and alkene, were also involved in the oligoaniline-containing polymers to improve their electrochromic properties, including color range, switching time, and stability [20-22]. The interaction and synergistic action between oligoaniline and functional groups were the main cause for the improvement of electrochromic performance.

To develop new polymeric structures bearing oligoaniline segments, and accurately determine their structure-property correlation, in this report, we synthesize a new electrochromic polyamic acid containing oligoaniline segments in the main chain via oxidative coupling polymerization. Then various additional functional groups, including tetraaniline, polyhedral oligomeric silsesquioxane (POSS), and fluorene, were introduced in the polymeric architecture through the post-polymerization functionalization strategy, respectively. Some key parameters of electrochromic properties were modulated effectively by virtue of these pendant functional groups. Moreover, novel electrofluorochromic behavior was also disclosed and investigated, ascribed to the pendant fluorene groups.

\section{Experimental}

\subsection{Materials}

1,2,4,5-Cyclohexanetetracarboxylic acid dianhydride, 4-aminodiphenylamine, $p$-phenylenediamine, 2-aminofluorene, $N, N^{\prime}$-dicyclohexylcarbodiimide (DCC), 4-dimethylaminopyridine (DMAP) and ferric chloride were purchased from Aladdin. Aminopropylisobutyl POSS $(M=874.58)$ was purchased from Hybrid Plastics Inc. The hydrochloric acid (37\%), ammonia solution (28\%) and hydrazine hydrate $(80 \%)$ were bought from Beijing Chemical Works. The tetraaniline was synthesized in our laboratory via the oxidative coupling method described in previous report [23]. Optically transparent indiumtin oxide (ITO) glass substrates were purchased from Xiang Science \& Technology Co. Ltd (Shenzhen). All the solvents were purchased from commercial sources and used as received without further purification.

\subsection{Instruments}

The nuclear magnetic resonance spectra (NMR) were recorded on a Bruker-500 spectrometer using deuterated dimethyl sulfoxide (DMSO). Fouriertransform infrared spectra (FTIR) of these polymers were performed on BRUKER VECTOR 22 Spectrometer. Photoluminescence (PL) spectra were collected on F97Pro fluorospectro photometer (Lengguang, Shanghai). UV-vis spectra were run on a UV3101 PC spectrometer (SHIMADZU). Cyclic voltammetry $(\mathrm{CV})$ and electrochemical impendence spectroscopy (EIS) of the electrochromic polymers were run on a $\mathrm{CHI} 660 \mathrm{C}$ Electrochemical Workstation $(\mathrm{CH}$ Instruments, USA) with a conventional three-electrode cell, composed of an $\mathrm{Ag} / \mathrm{AgCl}$ reference electrode, a platinum wire counter electrode, and the polymers/ITO working electrode, respectively. The electrolyte in the electrochemical measurement was $0.5 \mathrm{M}$ sulfuric acid solution.

\subsection{Synthesis of electrochromic polyamic acids}

The electrochromic polyamic acid containing pentaaniline in the main chain were synthesized through amidation reaction, followed by oxidative coupling polymerization. Firstly, the oligoaniline-containing monomer (OCM) was prepared as follows: $2.1188 \mathrm{~g}$ (11.5 mmol) 4-aminodiphenylamine was dissolved in $20 \mathrm{~mL}$ dichloromethane under nitrogen atmosphere. Then $1.1201 \mathrm{~g}$ (5 mmol) 1,2,4,5-cyclohexanetetracarboxylic acid dianhydride was added into the above solution with the assistance of $30 \mathrm{~mL}$ dichloromethane at room temperature. The reaction was kept with magnetic stirring for another $3 \mathrm{~h}$. Finally, the mixture was filtered using Buchner funnel, followed by washing with dichloromethane for three times. The OCM was dried under dynamic vacuum at $40^{\circ} \mathrm{C}$ for $12 \mathrm{~h}$ ( $93 \%$ yield). The Characterization of OCM: ${ }^{1} \mathrm{H}$ NMR $\left(d_{6}\right.$-DMSO, ppm) $: \delta=11.90$ 
$(-\mathrm{COOH}), \delta=9.38(-\mathrm{CONH}-), \delta=7.96-7.87$ $(-\mathrm{NH}-), \delta=7.45-6.50(\mathrm{Ar}-\mathrm{H}), \delta=3.01-2.79$ $(>\mathrm{CH}-), \delta=2.12\left(-\mathrm{CH}_{2}-\right)$. FTIR $\left(\mathrm{KBr}, \mathrm{cm}^{-1}\right): 3393$ $\left(v_{\mathrm{N}-\mathrm{H}}\right), 3047\left(v_{\mathrm{C}-\mathrm{H}}\right), 1716\left(v_{\mathrm{C}=\mathrm{O}}\right), 1599\left(v_{\mathrm{C}=\mathrm{C}}\right), 1515$ $\left(v_{\mathrm{C}=\mathrm{C}}\right), 1303\left(v_{\mathrm{C}-\mathrm{N}}\right), 827\left(\delta_{\mathrm{C}-\mathrm{H}}\right), 747\left(\delta_{\mathrm{C}-\mathrm{H}}\right), 695$ $\left(\delta_{\mathrm{C}-\mathrm{H}}\right)$.

The oxidative coupling polymerization proceeded as follows: $1.7598 \mathrm{~g}$ ( $3 \mathrm{mmol})$ OCM, $0.3244 \mathrm{~g}(3 \mathrm{mmol})$ $p$-phenylenediamine and $20 \mathrm{~mL}$ dimethylacetamide (DMAc) were added into a $250 \mathrm{~mL}$ round-bottom flask with magnetic stirring. Then $40 \mathrm{~mL} 1.5 \mathrm{M}$ hydrochloric acid was added dropwise into the above solution. $1.3692 \mathrm{~g} \mathrm{(6} \mathrm{mmol)} \mathrm{Ammonium} \mathrm{persulphate}$ was dissolved in $16 \mathrm{~mL} 1.0 \mathrm{M}$ hydrochloric acid solution to form the oxidant solution. The prepared oxidant solution was then added into the flask dropwise with a period of $20 \mathrm{~min}$. After the reaction proceeded for $12 \mathrm{~h}$ at room temperature, the resultant mixture was poured into $200 \mathrm{~mL}$ distilled water. The crude product was collected with filtration, and then washed with distilled water, acetone for 2 times. Then the obtained product was dedoped using $1.0 \mathrm{M}$ ammonia solution, and reduced by $1.0 \mathrm{M}$ hydrazine hydrate in $1.0 \mathrm{M}$ ammonia solution for $10 \mathrm{~h}$. Finally, the polymer was stirred in hydrochloric acid solution $(\mathrm{pH}=4)$ for $2 \mathrm{~h}$, and then dedoped using DMAc. The solid product could be obtained using precipitation method. The resultant polymer was defined as ECPA. The characterization of ECPA: ${ }^{1} \mathrm{H}$ NMR $\left(d_{6^{-}}\right.$ DMSO, ppm): $\delta=11.90(-\mathrm{COOH}), \delta=9.68$ and $9.28(-\mathrm{CONH}-), \delta=8.34(-\mathrm{NH}-), \delta=7.96(-\mathrm{NH}-$ )$, \delta=7.41-6.68(\mathrm{Ar}-\mathrm{H}), \delta=3.15-2.72(>\mathrm{CH}-), \delta=$ $2.13\left(-\mathrm{CH}_{2}-\right)$. FTIR $\left(\mathrm{KBr}, \mathrm{cm}^{-1}\right): 3344\left(\mathrm{v}_{\mathrm{N}-\mathrm{H}}\right), 3015$ $\left(v_{\mathrm{C}-\mathrm{H}}\right), 1706\left(v_{\mathrm{C}-\mathrm{O}}\right), 1593\left(v_{\mathrm{C}-\mathrm{C}}\right), 1506\left(v_{\mathrm{C}-\mathrm{C}}\right), 1304$ $\left(v_{\mathrm{C}-\mathrm{N}}\right), 820\left(\delta_{\mathrm{C}-\mathrm{H}}\right), 748\left(\delta_{\mathrm{C}-\mathrm{H}}\right), 699\left(\delta_{\mathrm{C}-\mathrm{H}}\right)$.

The post-polymerization functionalization technique was carried out to modify the polymeric architecture using tetraaniline, POSS, and fluorene. The resultant polymers were defined as ECPA-TA, ECPA-POSS, and ECPA-F, respectively. A typical synthesis procedure of ECPA-TA was as follows. $1 \mathrm{~mL} 0.045 \mathrm{M}$ DMAP DMAc solution was added dropwise into $1 \mathrm{~mL} 0.2 \mathrm{M}$ ECPA DMAc solution with magnetic stirring under $\mathrm{N}_{2}$ atmosphere $\left(0-5^{\circ} \mathrm{C}\right.$, cooled by icebath). After the mixture restoring to room temperature, $1 \mathrm{~mL}$ DMAc containing $0.45 \mathrm{mmol} \mathrm{TA}$ and 0.45 mmol DCC was added into the above mixture. Then the reaction proceeded for $12 \mathrm{~h}$ at room temperature. The resultant ECPA-TA was collected by precipitation method. The excessive pendant reagents was then removed by washing with ethanol. ECPAPOSS and ECPA-F were also synthesized readily using the same procedure, the pendant groups were POSS, and fluorene, respectively. It is worthwhile to note that only $0.04 \mathrm{mmol}$ POSS groups were involved in the post-polymerization functionalization process.

The characterization of ECPA-TA: ${ }^{1} \mathrm{H}$ NMR $\left(d_{6}\right.$ DMSO, ppm): $\delta=\delta=9.62$ and $9.37(-\mathrm{CONH}-), \delta=$ $8.34(-\mathrm{NH}-), \delta=7.95(-\mathrm{NH}-), \delta=7.43-6.53(\mathrm{Ar}-\mathrm{H})$, $\delta=3.15-2.72(>\mathrm{CH}-), \delta=2.13\left(-\mathrm{CH}_{2}-\right)$. FTIR $\left(\mathrm{KBr}, \mathrm{cm}^{-1}\right): 3330\left(v_{\mathrm{N}-\mathrm{H}}\right), 3029\left(v_{\mathrm{C}-\mathrm{H}}\right), 1710\left(v_{\mathrm{C}=\mathrm{O}}\right)$, $1602\left(v_{\mathrm{C}=\mathrm{C}}\right), 1506\left(v_{\mathrm{C}=\mathrm{C}}\right), 1308\left(v_{\mathrm{C}-\mathrm{N}}\right), 817\left(\delta_{\mathrm{C}-\mathrm{H}}\right)$, $748\left(\delta_{\mathrm{C}-\mathrm{H}}\right), 694\left(\delta_{\mathrm{C}-\mathrm{H}}\right)$.

The characterization of ECPA-POSS: ${ }^{1} \mathrm{H}$ NMR $\left(d_{6^{-}}\right.$ DMSO, ppm): $\delta=11.86(-\mathrm{COOH}), \delta=9.68$ and 9.32 $(-\mathrm{CONH}-), \delta=8.34(-\mathrm{NH}-), \delta=7.95(-\mathrm{NH}-), \delta=$ 7.45-6.68 ( $\mathrm{Ar}-\mathrm{H}), \delta=3.11-2.70(>\mathrm{CH}-), \delta=2.13$ $\left(-\mathrm{CH}_{2}-\right), \delta=1.79(>\mathrm{CH}-$ from POSS $), \delta=0.91\left(-\mathrm{CH}_{3}\right.$ from POSS $), \delta=0.58\left(-\mathrm{CH}_{2}-\right.$ from POSS). FTIR $\left(\mathrm{KBr}, \mathrm{cm}^{-1}\right): 3320\left(v_{\mathrm{N}-\mathrm{H}}\right), 3034\left(v_{\mathrm{C}-\mathrm{H}}\right), 1711\left(v_{\mathrm{C}=\mathrm{O}}\right)$, $1600\left(v_{\mathrm{C}=\mathrm{C}}\right), 1511\left(v_{\mathrm{C}=\mathrm{C}}\right), 1308\left(v_{\mathrm{C}-\mathrm{N}}\right), 1107\left(v_{\mathrm{Si}-\mathrm{O}-\mathrm{Si}}\right)$, $837\left(\delta_{\mathrm{C}-\mathrm{H}}\right), 746\left(\delta_{\mathrm{C}-\mathrm{H}}\right), 690\left(\delta_{\mathrm{C}-\mathrm{H}}\right)$.

The characterization of ECPA-F: ${ }^{1} \mathrm{H}$ NMR $\left(d_{6^{-}}\right.$ DMSO, ppm): $\delta=9.68$ and $9.30(-\mathrm{CONH}-), \delta=8.34$ $(-\mathrm{NH}-), \delta=7.94(-\mathrm{NH}-), \delta=7.45-6.68(\mathrm{Ar}-\mathrm{H}), \delta=$ $4.07\left(-\mathrm{CH}_{2}-\right.$ from fluorene $), \delta=3.11-2.70(>\mathrm{CH}-)$, $\delta=2.13\left(-\mathrm{CH}_{2}-\right)$. FTIR $\left(\mathrm{KBr}, \mathrm{cm}^{-1}\right): 3328\left(v_{\mathrm{N}-\mathrm{H}}\right)$, $3047\left(v_{\mathrm{C}-\mathrm{H}}\right), 1711\left(v_{\mathrm{C}=\mathrm{O}}\right), 1607\left(v_{\mathrm{C}=\mathrm{C}}\right), 1511\left(v_{\mathrm{C}=\mathrm{C}}\right)$, $1310\left(v_{\mathrm{C}-\mathrm{N}}\right), 824\left(\delta_{\mathrm{C}-\mathrm{H}}\right), 749\left(\delta_{\mathrm{C}-\mathrm{H}}\right), 697\left(\delta_{\mathrm{C}-\mathrm{H}}\right)$.

\section{Results and discussion}

\subsection{Synthesis and structure characterization}

As shown in Figure 1, the oligoaniline-containing electrochromic polyamic acid was firstly synthesized via oxidative coupling polymerization. Then the postpolymerization functionalization strategy was employed to modify the polymeric architectures via amidation reaction with the assistance of DCC/DMAP. Tetraaniline, POSS, and fluorene were utilized to improve the electrochromic performance and/or endow the polymer with new features. When the tetraaniline and fluorene were introduced in the polymeric architecture as pendants, all the carboxylic acid groups were exhausted in the amidation process. However, as for ECPA-POSS, only 10\% carboxylic acid groups reacted with POSS through the amidation method, due to a low feed ratio. The structures of these polymers were confirmed by FTIR, and ${ }^{1} \mathrm{H}$ NMR (Figure 2). The FTIR spectra of these polymers display 

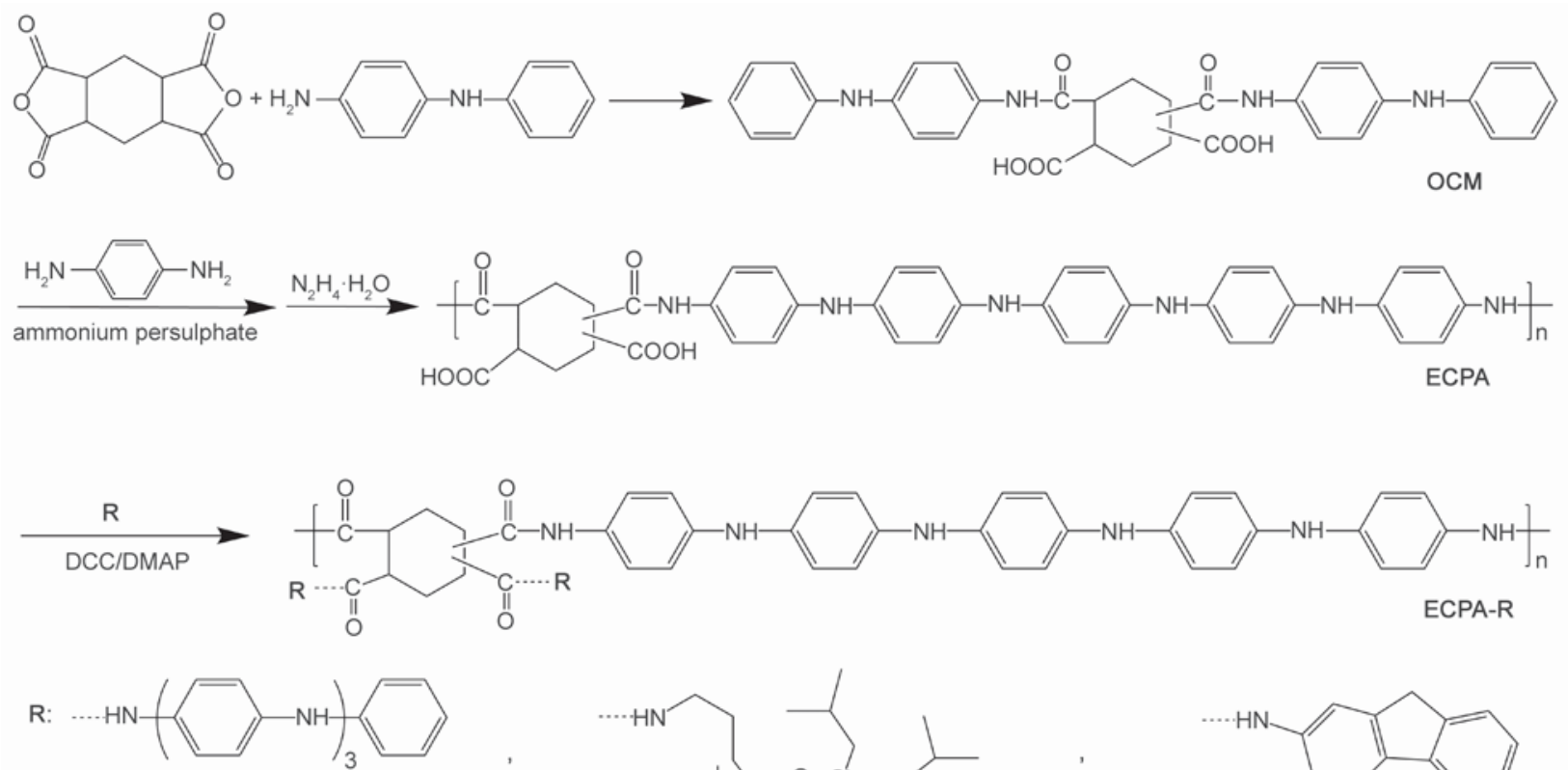

tetraanilie
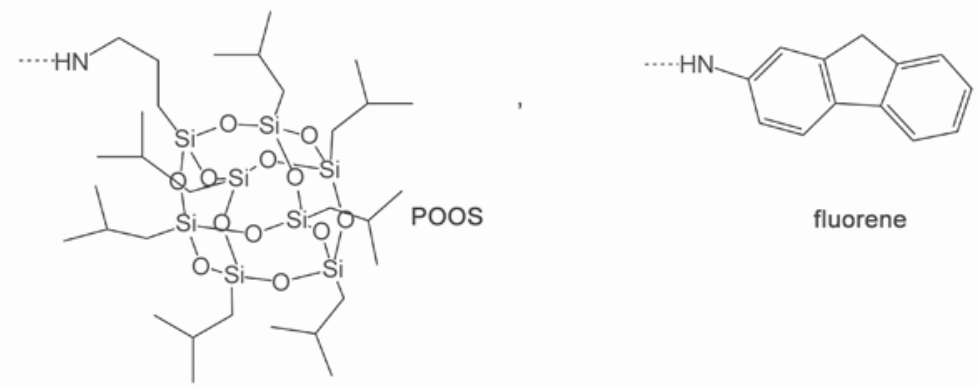

fluorene

Figure 1. Synthetic route of the electrochromic polymers bearing various functional pendants.

characteristic $\mathrm{N}-\mathrm{H}$ stretching vibration in the range of 3344-3320 $\mathrm{cm}^{-1}$, and C-H stretching vibration of aromatic groups around $3030 \mathrm{~cm}^{-1}$. The stretching vibrations of $\mathrm{C}=\mathrm{C}$ groups in the aryl groups are found around 1600 and $1500 \mathrm{~cm}^{-1}$. Moreover, the characteristic $\mathrm{C}-\mathrm{N}$ stretching vibration appears around $1310 \mathrm{~cm}^{-1}$. In the ${ }^{1} \mathrm{H}$ NMR spectra of ECPA, the signals at 11.86 and $9.68 \mathrm{ppm}$ are attributed to the proton of carboxylic acid and amide group in the main chain, respectively. The characteristic signals from amine groups can be observed around 8.34 and
$7.96 \mathrm{ppm}$. The signals in the range of 7.41-6.68 ppm are ascribed to the protons of aryl groups. The signals of methine and methylene groups from 1,2,4,5cyclohexanetetracarboxylic acid moiety are revealed around 3.15-2.72 and $2.13 \mathrm{ppm}$, respectively. After modifying with pendant tetraaniline, the ratio of aromatic signals increase obviously in the ${ }^{1} \mathrm{H}$ NMR spectra as expected (Figure 2a). While the signal about carboxylic acid vanishes thoroughly. Similar change is also found in the ${ }^{1} \mathrm{H}$ NMR spectra of ECPA-F. And the signal of methylene group from fluorene groups

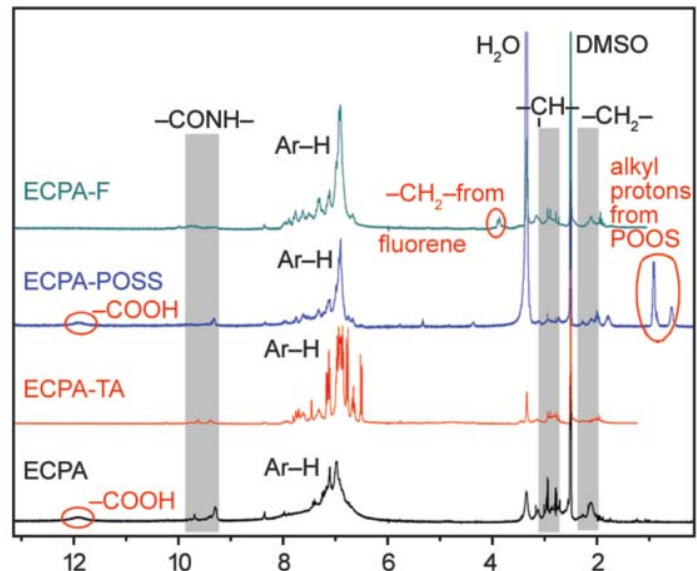

a)

Chemical shift [ppm]

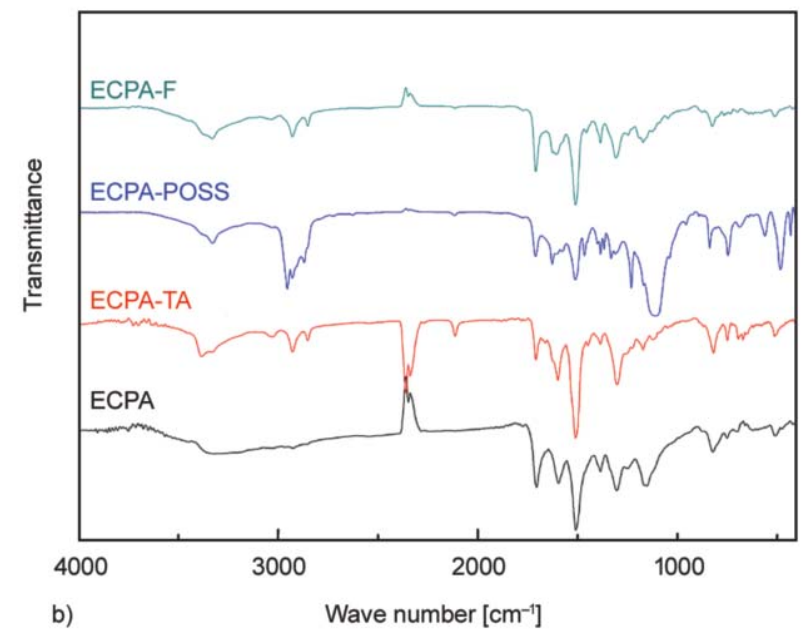

b)

Figure 2. a) ${ }^{1} \mathrm{H}$ NMR and b) FTIR spectra of ECPA, ECPA-TA, ECPA-POSS, and ECPA-F. 
is disclosed around $4.07 \mathrm{ppm}$. As for ECPA-POSS, although the quantity of POSS pendants is controlled at $10 \%$ of carboxylic acid, some alkyl signals are easily found around $1.79,0.91$, and $0.58 \mathrm{ppm}$ in the ${ }^{1} \mathrm{H}$ NMR spectra, due to the alkyl protons from POSS group. All the characterization data from FTIR, and ${ }^{1} \mathrm{H}$ NMR spectra certify the proposed molecular structure of these electrochromic polymers. Due to their large size of pendants, these electrochromic polymers show good solubility in various polar solvents including DMF, dimethylacetamide (DMF), DMAc, DMSO, $N$-methyl-2-pyrrolidinone (NMP).

\subsection{Electrochemical activity}

The cyclic voltammetry was employed to investigate the electrochemical activity of these electrochromic polymers coatings using the conventional three-electrode system. As shown in Figure 3a, the CV curve of ECPA/ITO displays three pairs of redox peaks at $0.28 \mathrm{~V} / 0.19 \mathrm{~V}, 0.52 \mathrm{~V} / 0.47 \mathrm{~V}$, and $0.70 \mathrm{~V} / 0.62 \mathrm{~V}$, ascribed to the transition of reduced leucoemeraldine form (LEB, no quinoid ring in oligoaniline segment) to half-oxidized emeraldine form I (EB I, one quinoid ring in oligoaniline segment), EB I to EB II (two quinoid rings in oligoaniline segment), and EB II to fully oxidized pernigraniline (PNB, three quinoid rings in the oligoaniline segment), respectively. Their corresponding structures of these four redox states are depicted in the Figure 4. Generally, polyaniline exists three idealized oxidation states, i.e. LEB, EB, and $\mathrm{PNB}$, and reveals two pairs of redox peaks at $0.21 \mathrm{~V} / 0.10 \mathrm{~V}$, and $0.75 \mathrm{~V} / 0.65 \mathrm{~V}$. Unlike polyaniline, ECPA could access four redox states due to its unique repeat unit with five benzoid rings. After the tetraaniline was introduced into polymeric structure

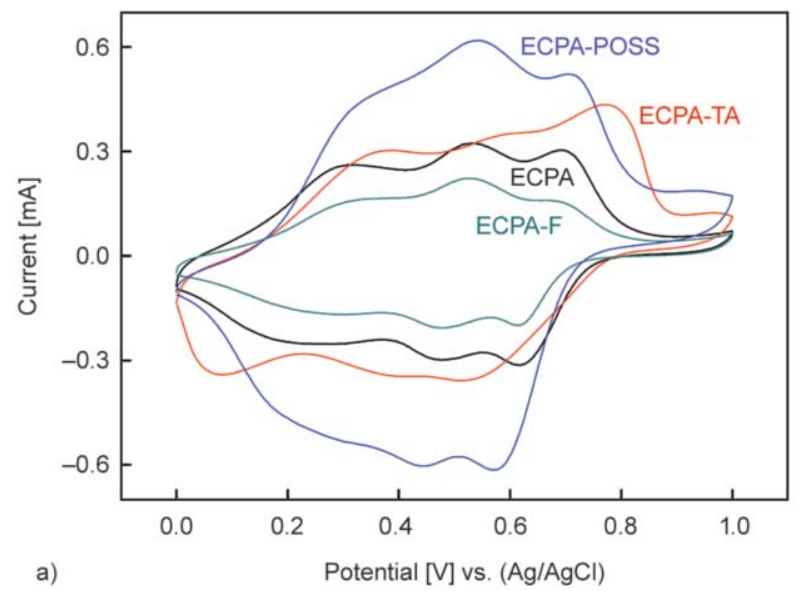

as the pendants, the resultant ECPA-TA shows a very different $\mathrm{CV}$ curve. The oxidant peaks undergo an obvious positive shift (move to $0.38,0.58$, and $0.78 \mathrm{~V}$, respectively). Conversely, the reduced peaks underwent negative shift drastically (move to $0.06,0.38$, and $0.53 \mathrm{~V}$, respectively). This abnormal phenomenon can be related to complicated molecular transition deriving from the combination of pentaaniline and tetraaniline segments (Figure 4). Moreover, the CV curve of ECPA-TA with more oligoaniline segment reveals increased peak currents, indicating high electrochemical activity. In addition, the increasing amplitude of peak current about EB II/PNB is greater than other two transitions, also attributed to the complicated molecular transition of ECPA-TA under potentials. Compared with ECPA/ITO electrode, an obvious current enhancement phenomenon was observed for the redox peaks of ECPA-POSS. The large size of the pendant POSS groups would weaken the intermolecular aggregation, which effectively enhance the electrolyte migration through the polymer film. When the flat fluorene groups were introduced into the polymeric structure, the stronger $\pi$-stacking interaction lead to a compact intermolecular aggregation, resulting in a weak electrolyte migration through the polymer film.

Furthermore, the polymer/ITO electrodes are examined carefully by EIS measurements. All the Nyquist plots were fitted by Randles type equivalent circuit model, which are usually used to simulate the experimental data at the initial state. The film resistances $\left(R_{\mathrm{f}}\right)$ of polymers are determined by intersecting point with $\mathrm{X}$-axis at the low-frequency end of the semicircle arc. As shown in Figure 3b, the Nyquist plot of ECPA disclose a $R_{\mathrm{f}}$ of $589 \Omega$. After introduced of

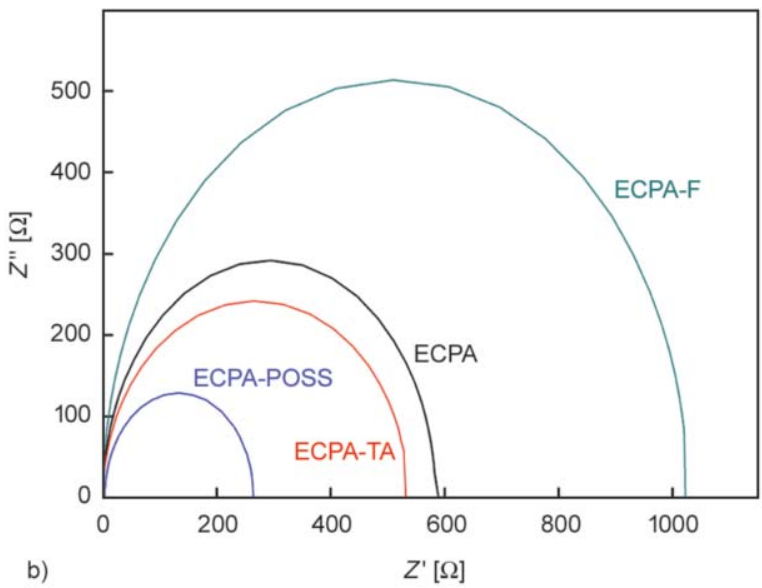

Figure 3. a) CV and b) EIS of polymer/ITO electrodes (ECPA, ECPA-TA, ECPA-POSS, ECPA-F) in $0.5 \mathrm{M} \mathrm{H}_{2} \mathrm{SO}_{4}$ solution. The potential scan rate in the $\mathrm{CV}$ measurement was set at $100 \mathrm{mV} / \mathrm{s}$. 

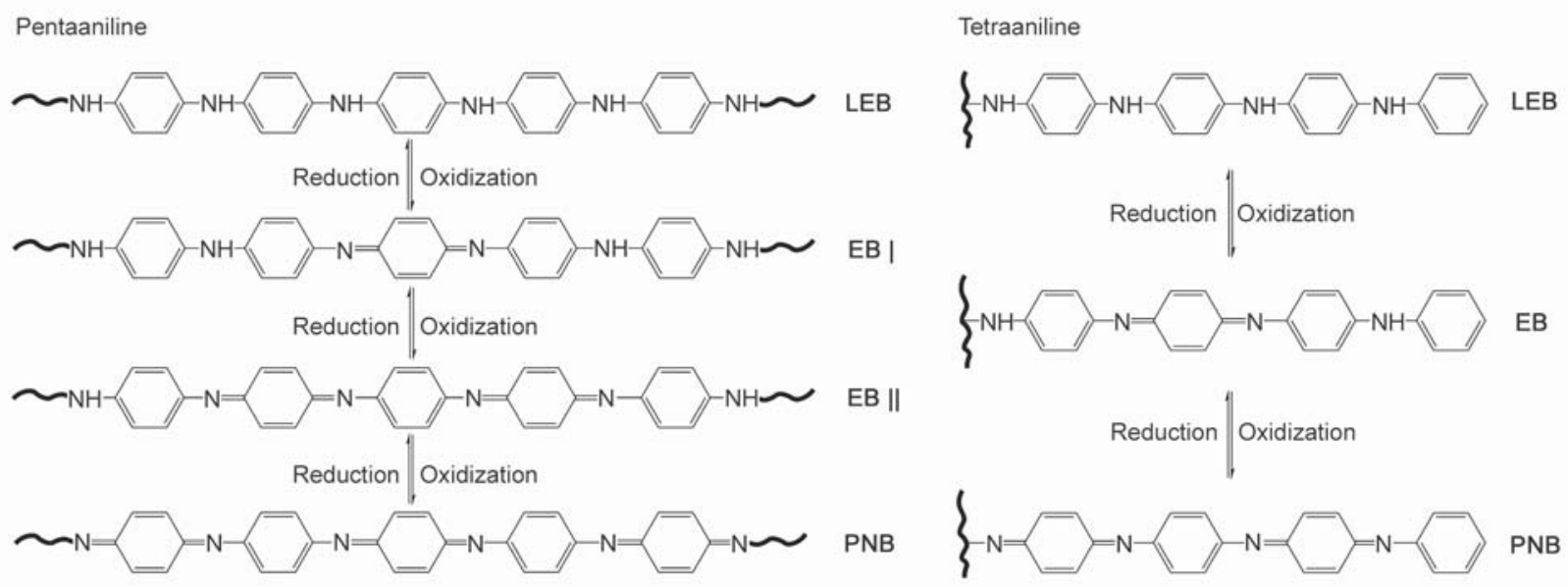

Figure 4. The molecular structures of pentaaniline and tetraaniline at various redox states.

tetraaniline, POSS, and fluorene pendants, the resulting polymers reveal varying $R_{\mathrm{f}}$ values of $532 \Omega$ (ECPA-TA), $264 \Omega$ (ECPA-POSS), and $1022 \Omega$ (ECPA-F), respectively. All the EIS results are in accord with their $\mathrm{CV}$ behaviors.

\subsection{Electrochromic performance}

Their electrochromic behavior was investigated on the electrochemical workstation in conjunction with the acquisition of UV-vis spectral data. Firstly, the spectroelectrochemical technology was carried out on these electrochromic electrodes with applied potentials of $-0.2,0,0.2,0.4,0.6,0.8$, and $1.0 \mathrm{~V}$ (vs. $\mathrm{Ag} / \mathrm{AgCl}$ ). Here, the residence time was fixed at 300 s. As shown in Figure 5a, the ECPA/ITO electrode reveals an electrochromic behavior with a drastic transmittance changes at different applied potentials. Its maximum optical contrast value $(\% \Delta T)$ is about $36 \%$ at $700 \mathrm{~nm}$ between -0.2 and $0.6 \mathrm{~V}$. Unlike polyaniline, its optical contrast value reduces gradually with the potential increasing from 0.6 to $1.0 \mathrm{~V}$, which should be related to their unique redox states transitions in the oligoaniline segments under applied potentials. Meanwhile, the color of ECPA/ITO electrode changes from gray $(-0.2 \mathrm{~V})$, to green $(0.4 \mathrm{~V})$ and finally to dark blue $(0.6 \mathrm{~V})$. After functionalization with these pendant groups, the resultant polymers display very similar electrochromic behavior. Obviously, ECPA-TA reveals an increased optical contrast value of $53 \%$, attributed to the introduction of electrochromic tetraaniline pendants.

To further explore their electrochromic properties, spectrochronoamperometry technology was performed on these polymer/ITO electrodes. In this measurement, the transmittance changes at $700 \mathrm{~nm}$ were monitored with the potential switching from

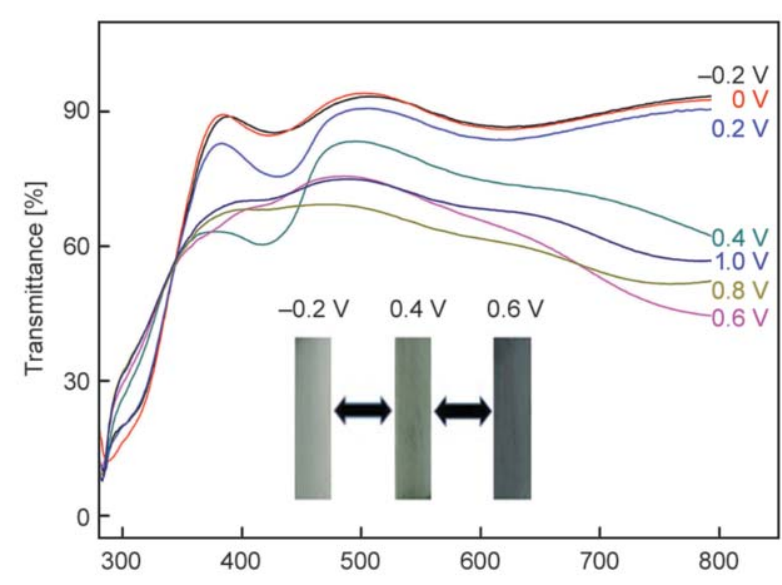

a)

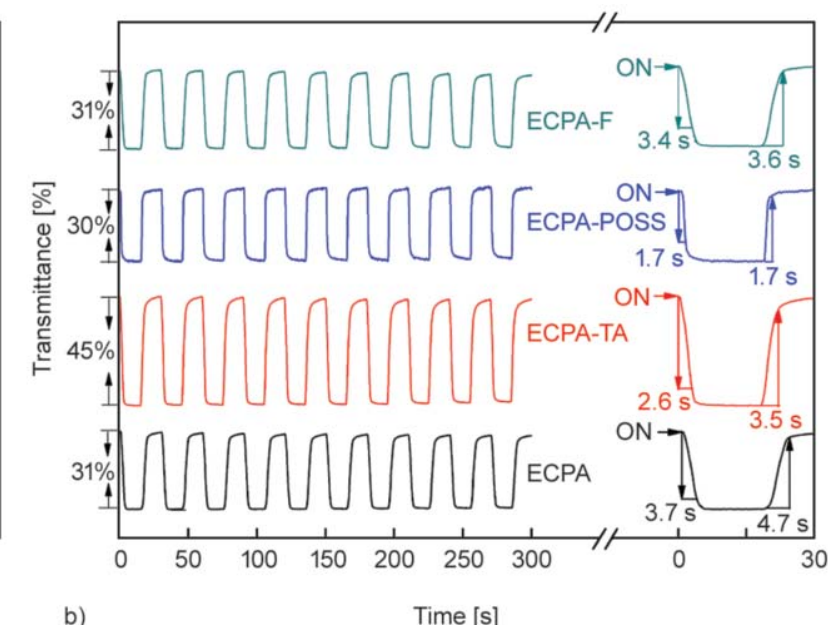

Figure 5. a) The spectral changes of ECPA/ITO electrode at different potentials with a residence time of $300 \mathrm{~s}$, and the inset shows photographs of electrochromic electrode at different potentials. b) The absorbance changes of the first $10 \mathrm{cy}-$ cles monitored at $700 \mathrm{~nm}$ of electrochromic electrodes when the applied potential was switched between -0.2 and $0.6 \mathrm{~V}$ with a residence time of $15 \mathrm{~s}$. 

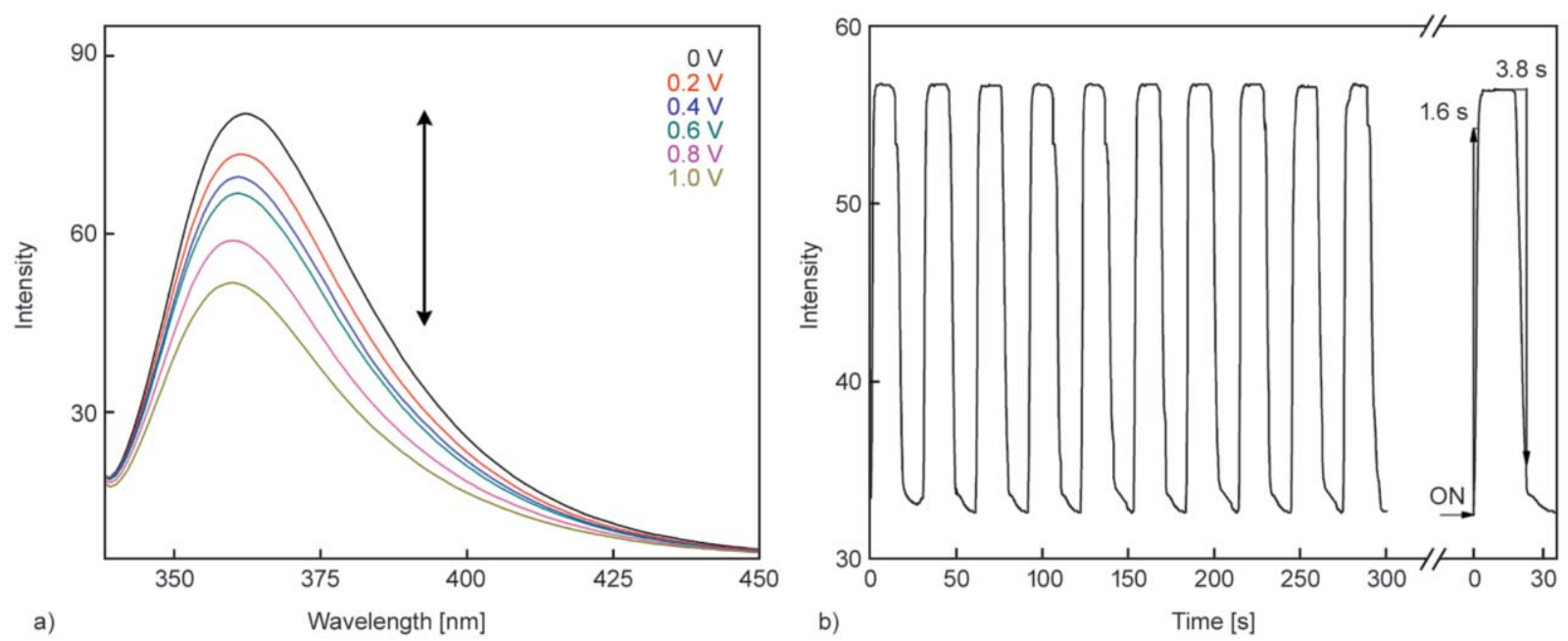

Figure 6. a) Fluorescence spectra of ECPA-F/ITO at different potentials from 0.0 to $1.0 \mathrm{~V}$ with a residence time of $300 \mathrm{~s}$. The excitation wavelength is $320 \mathrm{~nm}$. b) Fluorescence change monitored at $363 \mathrm{~nm}$ of ECPA-F films under the repeated potentials stepping of 0 and $1.0 \mathrm{~V}$ with a residence time of $15 \mathrm{~s}$.

-0.2 to $0.6 \mathrm{~V}$. The residence time was fixed at $15 \mathrm{~s}$. From the first ten cycles of these electrodes (Figure $5 \mathrm{~b}$ ), the optical contrast value are determined about 31\% (ECPA), 45\% (ECPA-TA), 30\% (ECPAPOSS), and $31 \%$ (ECPA-F), respectively. With the addition of current consumption, the coloration efficiency of these polymers are calculated to be $47 \mathrm{~cm}^{2} / \mathrm{C}$ (ECPA), $66 \mathrm{~cm}^{2} / \mathrm{C}$ (ECPA-TA), $53 \mathrm{~cm}^{2} / \mathrm{C}$ (ECPA-POSS), and $57 \mathrm{~cm}^{2} / \mathrm{C}$ (ECPA-F), respectively. Although the resulting coloration efficiency values are quite low compared to recent results from conjugated electrochromic polymers $[4,24,25]$, the prepared polymer are still qualified as electrochromic material in the applications of light-adapting mirrors and smart windows. In addition, the switching speeds of the polymers are also determined from Figure $5 \mathrm{~b}$. Here, the switching time is defined as the time required for reaching $90 \%$ of the full change in coloring/bleaching process. As shown in Figure 5b, these polymers functioned with different pendant groups reveal moderate switching speeds of $3.7 \mathrm{~s} / 4.7 \mathrm{~s}$ (ECPA), $2.6 \mathrm{~s} / 3.5 \mathrm{~s}$ (ECPA-TA), $1.7 \mathrm{~s} / 1.7 \mathrm{~s}$ (ECPAPOSS), and $3.4 \mathrm{~s} / 3.6 \mathrm{~s}$ (ECPA-F), respectively. It is quite obvious that ECPA-POSS displays rapid switching speeds, attributed to the enhanced electrolyte migration in ECPA-POSS film during the electrochromic process.

In view of the fluorescence essence of fluorene pendants, the resultant ECPA-F was a potential electrofluorochromic material, whose fluorescence intensity could be switched reversibly upon the applied voltage. In this electrofluorochromic system, oligoaniline and fluorene are served as electroactive unit and fluorescence units, respectively. Therefore, both spectroelectrochemical technology and spectrochronoamperometry technology were applied on ECPA-F/ITO electrode to study its electrofluorochromic behavior. An obvious electrofluorochromic behavior is presented in Figure 6a, which is generated from the interplay between oligoaniline and fluorene groups. The fluorescence intensity at $363 \mathrm{~nm}$ decreases gradually with the increase of applied potential, and finally to $60 \%$ of its original value at $1.0 \mathrm{~V}$. Moreover, spectrochronoamperometry measurements were carried out by monitoring the fluorescence changes at $363 \mathrm{~nm}$ under the repeated potentials stepping of 0 and $1.0 \mathrm{~V}$ with a residence time of $15 \mathrm{~s}$. As shown in the Figure 6b, ECPA-F/ITO electrode exhibits a well fluorescence switching property with quick switching times of $1.6 \mathrm{~s} / 3.8 \mathrm{~s}$ for its on/off states. However, the absolute values of fluorescence intensity in this measurement were weaker than those in the spectroelectrochemical test, due to its shorter residence time of the applied potentials.

\section{Conclusions}

In summary, a series of novel electrochromic polymers were designed and synthesized by oxidative coupling polymerization coupled with post-polymerization functionalization. Several functional groups were introduced into the polymeric architecture, resulting in an enhancement of electrochromic properties, such as improved coloration efficiency, high optical contrast value and rapid switching rate. Moreover, a new electrofluorochromic feature was achieved by virtue of fluorescence fluorene groups. 
Based on these clear structure-function relationships, we will focus on the improvement of electro(fluoro)chromic performance of these oligoaniline-containing polymers in the future.

\section{Acknowledgements}

We gratefully acknowledge the National Natural Science Foundation of China for funding (grant no. 21774046) and the ' $13^{\text {th }}$ Five-Year' Science and Technology Research Project of the Education Department of Jilin Province (JJKH20170781KJ).

\section{References}

[1] Amb C. M., Dyer A. L., Reynolds J. R.: Navigating the color palette of solution-processable electrochromic polymers. Chemistry of Materials, 23, 397-415 (2011). https://doi.org/10.1021/cm1021245

[2] Beaujuge P. M., Reynolds J. R.: Color control in $\pi$-conjugated organic polymers for use in electrochromic devices. Chemical Reviews, 110, 268-320 (2010). https://doi.org/10.1021/cr900129a

[3] Lee J. Y., Han S-Y., Cho I., Lim B., Nah Y-C.: Electrochemical and electrochromic properties of diketopyrrolopyrrole-based conjugated polymer. Electrochemistry Communications, 83, 102-105 (2017). https://doi.org/10.1016/j.elecom.2017.09.009

[4] Yang X., Liu C., Guo J., Wang L., Nie G.: A free-standing electrochromic material of poly (5,7-bis(2-(3,4-ethylenedioxy)thienyl)-indole) and its application in electrochromic device. Journal of Polymer Science Part A: Polymer Chemistry, 55, 2356-2364 (2017).

https://doi.org/10.1002/pola.28624

[5] Suganya S., Kim N., Jeong J. Y., Park J. S.: Benzotriazole-based donor-acceptor type low band gap polymers with a siloxane-terminated side-chain for electrochromic applications. Polymer, 116, 226-232 (2017). https://doi.org/10.1016/j.polymer.2017.03.075

[6] Tian Y., Zhang X., Dou S., Zhang L., Zhang H., Lv h., Wang L., Zhao J., Li Y.: A comprehensive study of electrochromic device with variable infrared emissivity based on polyaniline conducting polymer. Solar Energy Materials and Solar Cells, 170, 120-126 (2017). https://doi.org/10.1016/j.solmat.2017.05.053

[7] Lü X., Yu P., Ouyang M., Qian L., Yan S., Jin X., Zhang C.: Electrochromic properties of polyaniline films on graphene-ITO composite electrode (in Chinese). Chemical Journal of Chinese Universities, 38, 694-700 (2017). https://doi.org/10.7503/cjcu20160636

[8] Díaz-Sánchez J., Rosas-Aburto A., Vivaldo-Lima E., Hernández-Alcántara J. M., Gracia-Mora I., VázquezTorres H., Ordóñez L. C., Roquero P., Gimeno M.: Development and characterization of a flexible electrochromic device based on polyaniline and enzymatically synthesized poly (gallic acid). Synthetic Metals, 223, 43-48 (2017).

https://doi.org/10.1016/j.synthmet.2016.11.038
[9] Zhang W., Ju W., Wu X., Wang Y., Wang Q., Zhou H., Wang S., Hu C.: Structure, stability and electrochromic properties of polyaniline film covalently bonded to indium tin oxide substrate. Applied Surface Science, 367, 542-551 (2016).

https://doi.org/10.1016/j.apsusc.2016.01.041

[10] Lin C-L., Liao L-J.: Preparation of micropatterned polyaniline thin films with enhanced electrochromic properties by electrostatic field-assisted potentiostatic deposition. Solar Energy Materials and Solar Cells, 145, 54-60 (2016). https://doi.org/10.1016/j.solmat.2015.07.035

[11] Pinit J., Paradee N., Sirivat A.: Electrochromic characteristics of poly( $o$-toluidine) coated onto flexible indium tin oxide: Effect of $\mathrm{H}_{2} \mathrm{SO}_{4}$ and 1-butyl-3-methylimidazolium chloride electrolytes. Thin Solid Films, 616, 381-387 (2016). https://doi.org/10.1016/j.tsf.2016.08.057

[12] Mungkalodom P., Paradee N., Sirivat A., Hormnirun P.: Synthesis of poly (2,5-dimethoxyaniline) and electrochromic properties. Materials Research, 18, 669-676 (2015).

https://doi.org/10.1590/1516-1439.235513

[13] Huang L-M., Wen T-C., Gopalan A.: In situ UV-visible spectroelectrochemical studies on electrochromic behavior of poly(2,5-dimethoxy aniline). Synthetic Metals, 130, 155-163 (2002).

https://doi.org/10.1016/S0379-6779(02)00116-9

[14] Chen C., Hong X., Xu T., Lu L., Gao Y.: Electrosynthesis and electrochemical and electrochromic properties of poly(aniline-co- $\mathrm{N}$-methylthionine). Journal of the Electrochemical Society, 162, G54-G62 (2015). https://doi.org/10.1149/2.0861508jes

[15] Chotsuwan C., Asawapirom U., Shimoi Y., Akiyama H., Ngamaroonchote A., Jiemsakul T., Jiramitmongkon K.: Investigation of the electrochromic properties of triblock polyaniline-polythiophene-polyaniline under visible light. Synthetic Metals, 226, 80-88 (2017). https://doi.org/10.1016/j.synthmet.2017.02.001

[16] Gao J., Liu D-G., Sansiñena J-M, Wang H-L.: Synthesis and characterization of electrochromic polyamides with well-defined molecular structures and redox properties. Advanced Functional Materials, 14, 537-543 (2004). https://doi.org/10.1002/adfm.200305087

[17] Chao D., Jia X., Liu H., He L., Cui L., Wang C., Berda E. B.: Novel electroactive poly(arylene ether sulfone) copolymers containing pendant oligoaniline groups: Synthesis and properties. Journal of Polymer Science Part A: Polymer Chemistry, 49, 1605-1614 (2011). https://doi.org/10.1002/pola.24584

[18] Cao L., Gong C., Yang J.: A solution-processable (tetraaniline- $b$-polyethylene glycol) $)_{3}$ star-shaped rod-coil block copolymer with enhanced electrochromic properties. Macromolecular Rapid Communications, 37, 343-350 (2016). https://doi.org/10.1002/marc.201500564 
[19] Cao L., Gong C., Yang J.: Conducting tetraaniline derivatives with fast switching time, enhanced contrast and coloration efficiency. Electrochimica Acta, 192, 422 430 (2016).

https://doi.org/10.1016/j.electacta.2016.02.016

[20] Chao D., Zheng T., Liu H., Yang R., Jia X., Wang S., Berda E. B., Wang C.: A novel poly(aryl ether) containing azobenzene chromophore and pendant oligoaniline: Synthesis and electrochromic properties. Electrochimica Acta, 60, 253-258 (2012).

https://doi.org/10.1016/j.electacta.2011.11.052

[21] Chi M., Wang S., Liang Y., Chao D., Wang C.: Electroactive self-doped poly(amic acid) with oligoaniline and sulfonic acid groups: Synthesis and electrochemical properties. Journal of Colloid and Interface Science, 423, 7-12 (2014).

https://doi.org/10.1016/j.jcis.2014.02.021
[22] Yin M., Li F., Yan Y., Liu X., Wang C., Chao D.: Poly(aryl ether) bearing electroactive tetraaniline pendants and allyl groups: Synthesis, photo-crosslinking and electrochemical properties. Journal of Polymer Science part A: Polymer Chemistry, 54, 2321-2330 (2016). https://doi.org/10.1002/pola.28103

[23] Zhang W., Feng J., MacDiarmid A. G., Epstein A. J.: Synthesis of oligomeric anilines. Synthetic Metals, 84, 119120 (1997). https://doi.org/10.1016/S0379-6779(97)80674-1

[24] Soganci T., Gumusay O., Soyleyici H. C., Ak M.: Synthesis of highly branched conducting polymer architecture for electrochromic applications. Polymer, 134, 187195 (2018) https://doi.org/10.1016/j.polymer.2017.11.067

[25] Neo W. T., Ye Q., Wang X., Yan H., Xu J.: Low band-gap polymers incorporating benzotriazole and 5,6-dialkoxybenzothiadiazole as solution processable electrochromic materials. Express Polymer Letters, 9, 496-508 (2015). https://doi.org/10.3144/expresspolymlett.2015.48 